\title{
A Successive Conversion-De-Intercalation Delithiation Mechanism for Practical Composite Lithium Anodes
}

Peng Shi,${ }^{\dagger}$ Li-Peng Hou, ${ }^{\dagger}$ Cheng-Bin Jin, ${ }^{\dagger}$ Ye Xiao, ${ }^{\ddagger}, \S$ Yu-Xing Yao, ${ }^{\dagger}$ Jin Xie, ${ }^{\dagger}$ BoQuan Li, ${ }^{\ddagger} \S$ Xue-Qiang Zhang, ${ }^{\ddagger} \S^{*}$ and Qiang Zhang ${ }^{\dagger *}$

${ }^{\dagger}$ Beijing Key Laboratory of Green Chemical Reaction Engineering and Technology, Department of Chemical Engineering, Tsinghua University, Beijing 100084, China

\#Advanced Research Institute of Multidisciplinary Science, Beijing Institute of Technology, Beijing 100081, China

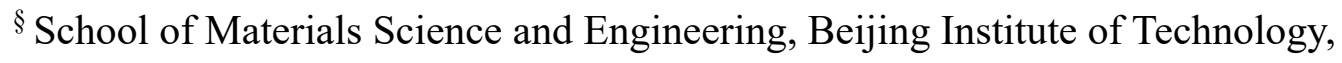
Beijing 100081, China 


\section{Supporting Text}

\section{Experimental Sections}

\subsection{Fabrication of Li Metal-Graphite ( $\mathrm{Li} / \mathrm{C})$ Composite Anode}

The Li metal-graphite $(\mathrm{Li} / \mathrm{C})$ composite anode with a bilayer structure was fabricated by the method of rolling. Both dried graphite electrodes (Hefei Kejing Materials Technology Co., Ltd) and ultrathin Li foils (99.9\%, China Energy Lithium Co., Ltd) were stacked and rolled in a roller press (Shenzhen Kejing Star Technology Co., Ltd). The rolling process was carried out in the dry room with a dew-point temperature of $-40^{\circ} \mathrm{C}$. The areal density of active material in graphite electrode is $5.0 \mathrm{mg} \mathrm{cm}^{-2}$. The thickness of ultrathin Li foil is $50 \mu \mathrm{m}$, and the bulk density of Li metal is $0.53 \mathrm{~g} \mathrm{~cm}^{-3}$.

\subsection{Material Characterizations}

The scanning electron microscope (SEM, JSM 7401F, JEOL, Japan) was employed to characterize the morphology of graphite, $\mathrm{Li}$, and $\mathrm{Li} / \mathrm{C}$ composite anode, which was operated at $3.0 \mathrm{kV}$. The X-ray diffraction (XRD) patterns were recorded on a Bruker D8 Avance diffractometer equipped with a $\mathrm{Cu}-\mathrm{K}_{\alpha}$ radiation source. The samples were protected by the polyimide tape during testing. The time-of-flight second ion mass spectroscopy (TOF-SIMS, ION-TOF GmbH) was employed to analyze the distribution of Li ions in the composite anode after the delithiation process. The semicircular graphite electrode was sputtered by a focused ion beam (FIB) before analysis to obtain the distribution of Li ions in the bulk graphite.

All samples obtained from disassembled cells were firstly cleaned by DME solvent three times, and then dried until the solvent was volatilized thoroughly in the glove box. 
During transferring process before characterizations, all samples were protected with Ar in a homemade container to avoid contacting with air.

\subsection{Electrochemical Measurements}

All coin cells were assembled with standard CR2025 coin-type cells in an Ar-filled glove box with $\mathrm{O}_{2}$ and $\mathrm{H}_{2} \mathrm{O}$ content below $0.1 \mathrm{ppm}$. The polypropylene film (Celgard 2400) was employed as the separator in all kinds of batteries in this work.

\subsubsection{Three-Electrode Test}

A three-electrode cell was designed, in which a $\mathrm{Li} / \mathrm{C}$ composite anode was served as the working electrode. A LiNi0.5 $\mathrm{Co}_{2 .} \mathrm{Mn}_{0.3} \mathrm{O}_{2}\left(\mathrm{NCM} 523,3.0 \mathrm{mAh} \mathrm{cm}^{-2}\right)$ disc and a Li@Cu wire were employed as a counter and reference electrode, respectively. Lithium hexafluorophosphate ( $\mathrm{LiPF}_{6}, 98 \%$ purity), fluoroethylene carbonate (FEC, 98\% purity), dimethyl carbonate (DMC, 99\% purity) were used in the electrolyte. The electrolyte was 1.0 M LiPF6 dissolved in FEC/DMC (1:4, by volume). The amount of electrolyte is $50 \mu \mathrm{L}$.

\subsubsection{Half-Cell Test}

A specific circular electrode comprising a semicircular Li metal and a semicircular graphite electrode was designed as the model system and illustrated in Figure 2a. A semicircle Li metal and graphite touch with each other along the diameter to block the diffusion of Li ion from Li metal to graphite compared to a bilayer structure.

The $\mathrm{Li} / \mathrm{C}$ composite anode was stamped into $15 \mathrm{~mm}$ diameter electrodes for symmetrical cells. And in the cell designed to test the average $\mathrm{CE}$ and reversible Li, an 
ultrathin Li electrode or a composite anode was employed as the working electrode and the thick Li electrode with a thickness of $600 \mu \mathrm{m}$ was the counter electrode.

\subsubsection{Full-Cell Test}

The $\mathrm{LiNi}_{0.5} \mathrm{Co}_{0.2} \mathrm{Mn}_{0.3} \mathrm{O}_{2}$ (NCM523) cathode with an areal capacity of $3.0 \mathrm{mAh} \mathrm{cm}{ }^{-2}$ was acquired from Guangdong Canrd New Energy Technology Co., Ltd, and was punched into discs with a diameter of $13 \mathrm{~mm}$. They were firstly cycled at $0.1 \mathrm{C}$ and then cycled at $0.4 \mathrm{C}$. The cells were monitored in galvanostatic mode within a voltage range of 2.8 to $4.3 \mathrm{~V}$. The charge/discharge tests of all coin cells were performed on a Neware BTS-51 multichannel battery tester (Shenzhen, Neware, BTS) in a testing room with a constant temperature of $25^{\circ} \mathrm{C}$. Localized high concentration electrolyte (LHCE) consists of lithium bis(fluorosulfonyl)imide (LiFSI, 99.9\%), dimethyl carbonate (DMC, 99.9\%), and 1,1,2,2-tetrafluoroethyl-2,2,3,3-tetrafluoropropylether (HFE, 99.9\%) with a mole ratio of 1.0: 1.8: 2.0, which was employed as the electrolyte. LiFSI and HFE were purchased from Suzhou Duoduo Chemical Technology Co., Ltd. The amount of electrolyte is $50 \mu \mathrm{L}$.

All pouch cells were assembled in a dry room with a dew-point temperature of $-40^{\circ} \mathrm{C}$. A layer-by-layer process has been used to alternate the cathodes and anodes with polypropylene membranes acting as the separator in pouch cells. All pouch cells were tested on a Land CT2001 multichannel battery tester (Wuhan Land Electronic Co., LTD.) in the environmental oven (Shanghai, Espec, Environmental Equipment Corp., SEG-021) with a constant temperature of $25^{\circ} \mathrm{C}$. The Li/C | NCM523 pouch cells were monitored within a voltage range of 3.0 to $4.3 \mathrm{~V}$. The thickness of the composite anode 
is around $90 \mu \mathrm{m}$ and the areal capacity of NCM523 is $4.0 \mathrm{mAh} \mathrm{cm}{ }^{-2}$ on each side. They were firstly cycled at $0.05 \mathrm{C}$ and then cycled at $0.1 \mathrm{C}$. The external pressure on the $\mathrm{Li} / \mathrm{C}$ | NCM523 pouch cells is $c a$. 1.0 MPa. The electrolyte was $1.0 \mathrm{M} \mathrm{LiPF}_{6}$ dissolved in FEC/DMC (1:4, by volume) and the amount of electrolyte in a pouch cell is $3.0 \mathrm{gAh}^{-1}$. 


\section{Supporting Figures}

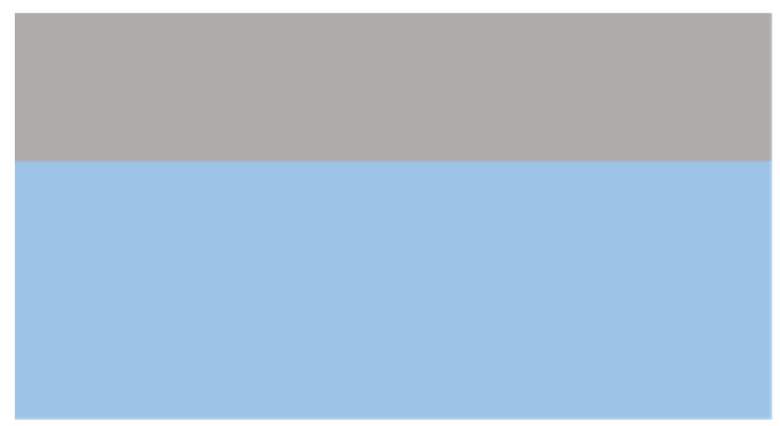

\section{Li metal Graphite}

Figure S1. Schematic illustration of the Li/C composite anode with a bilayer structure. Compared with the parallel structure, a vertical structure improves the intercalation rate of $\mathrm{Li}$ ions from Li metal to graphite due to the large contact area, which ensures that the CTD mechanism can consistently work. In addition, only the upper graphite layer can contact liquid electrolytes and be involved into the achievement of CTD delithiation mechanism. Therefore, the bilayer structure is employed in this work. 


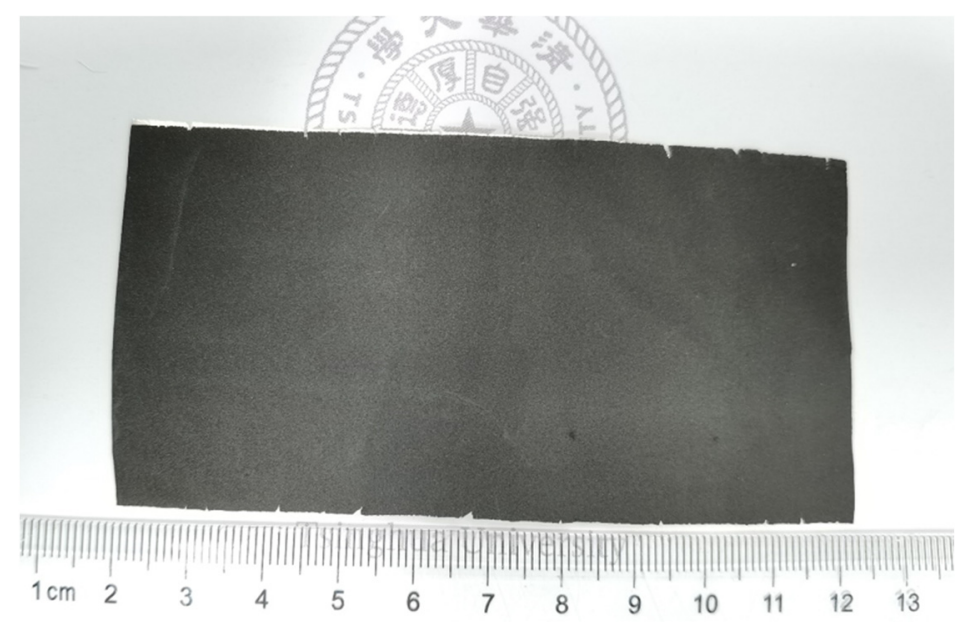

Figure S2. Digital image of the $\mathrm{Li} / \mathrm{C}$ composite electrode. 
a

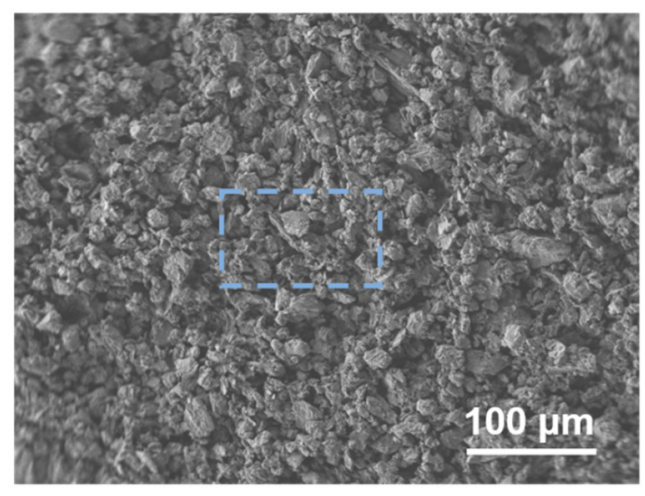

b

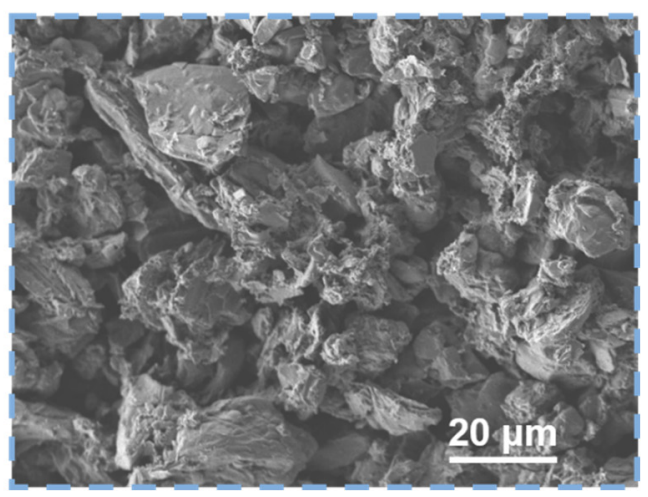

Figure S3. The morphology of (a) graphite electrode and (b) partial enlarged image. 


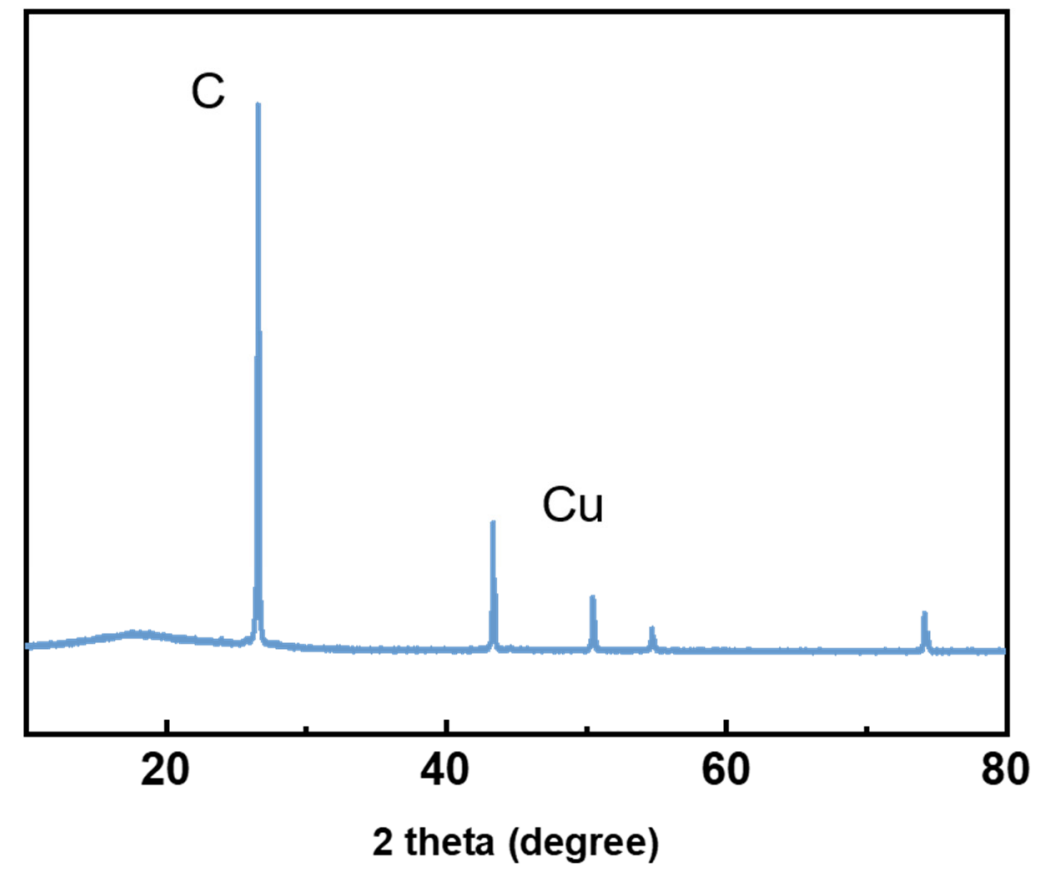

Figure S4. XRD pattern of the graphite electrode on $\mathrm{Cu}$ collector. 
Three-electrode testing

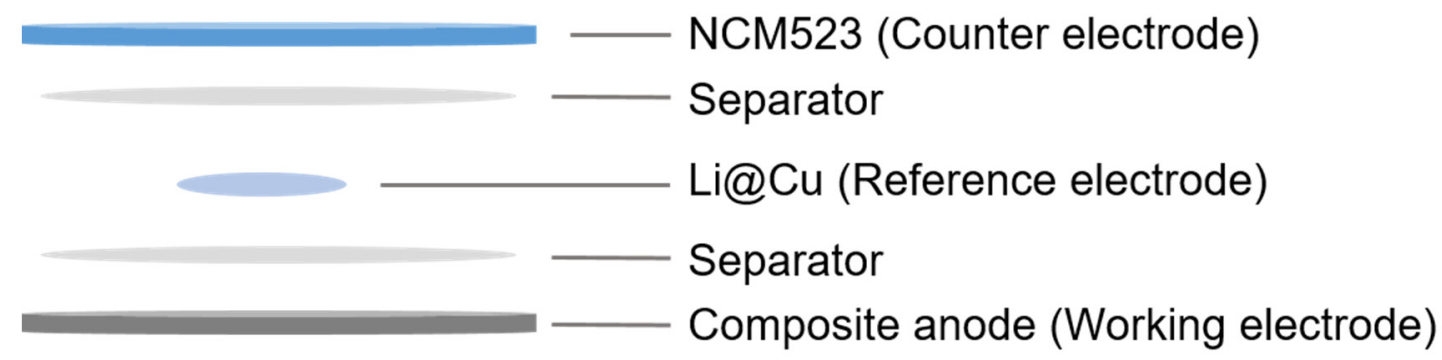

Figure S5. Schematic illustration of the three-electrode testing device. 


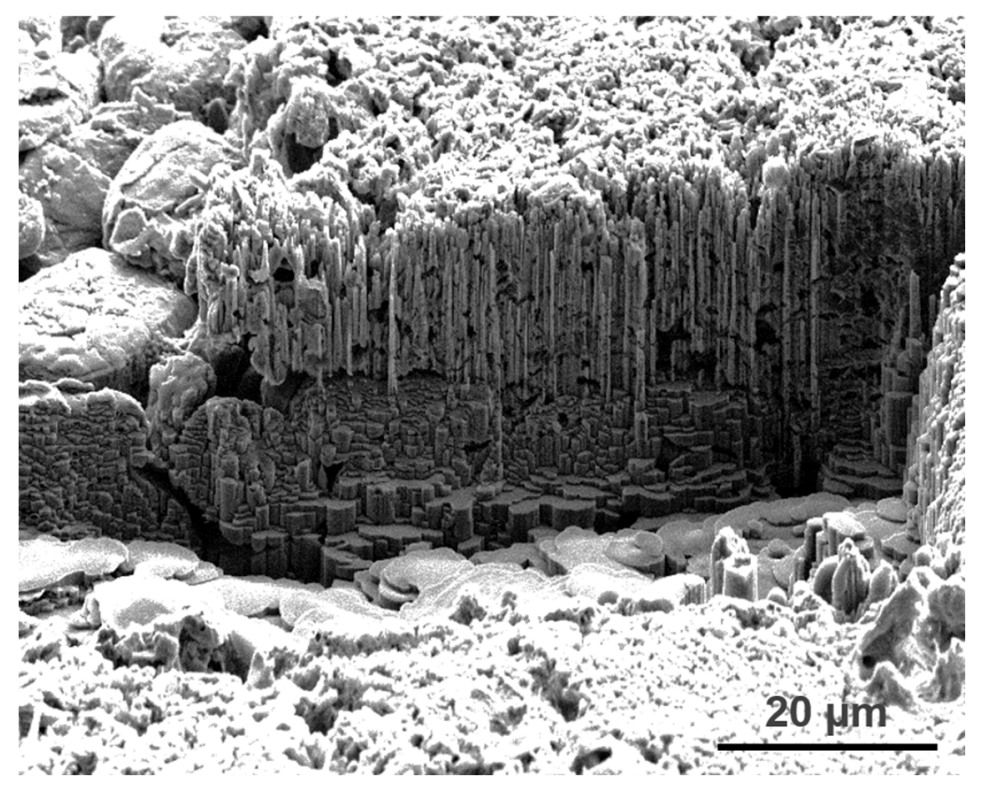

Figure S6. The cross-sectional SEM image of semicircular delithiated graphite electrode after sputtering. 


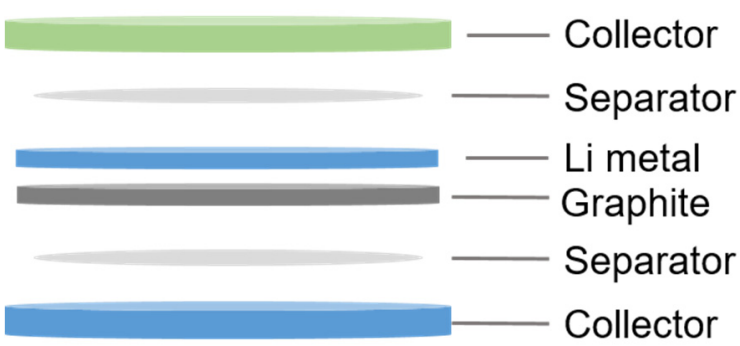

Figure S7. The configuration of the cells which are employed to investigate the kinetics of the reformation of $\mathrm{LiC}_{6}$. 


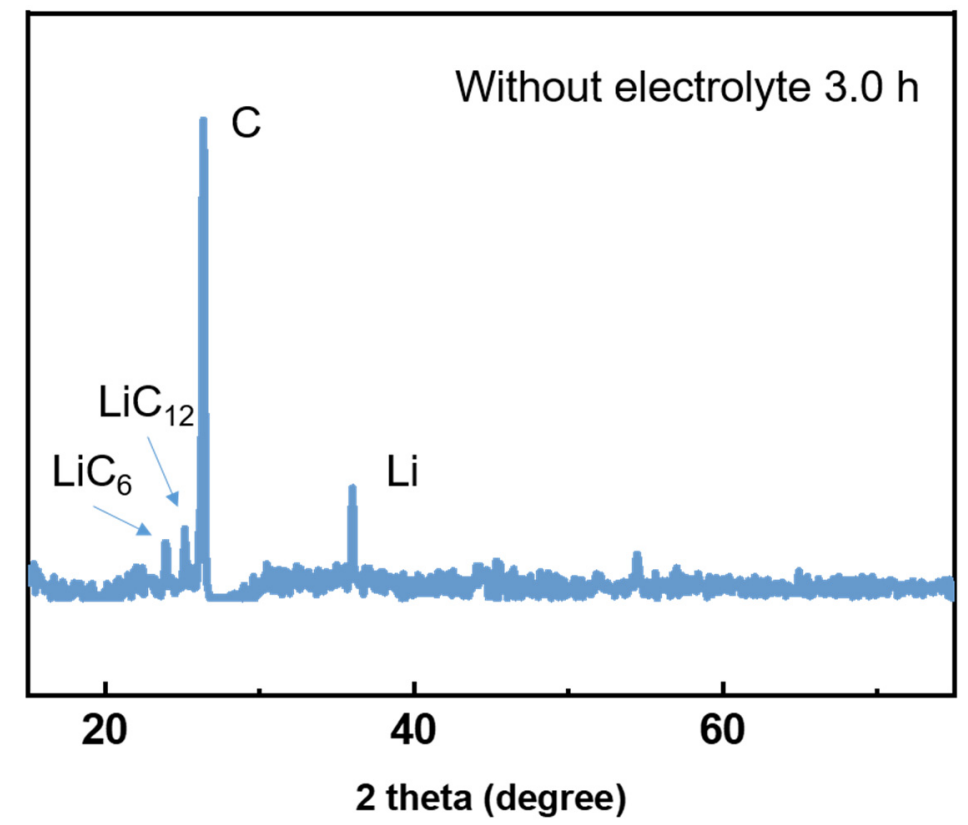

Figure S8. The XRD pattern of the graphite electrode after $3.0 \mathrm{~h}$ in coin cells without electrolyte. 
a
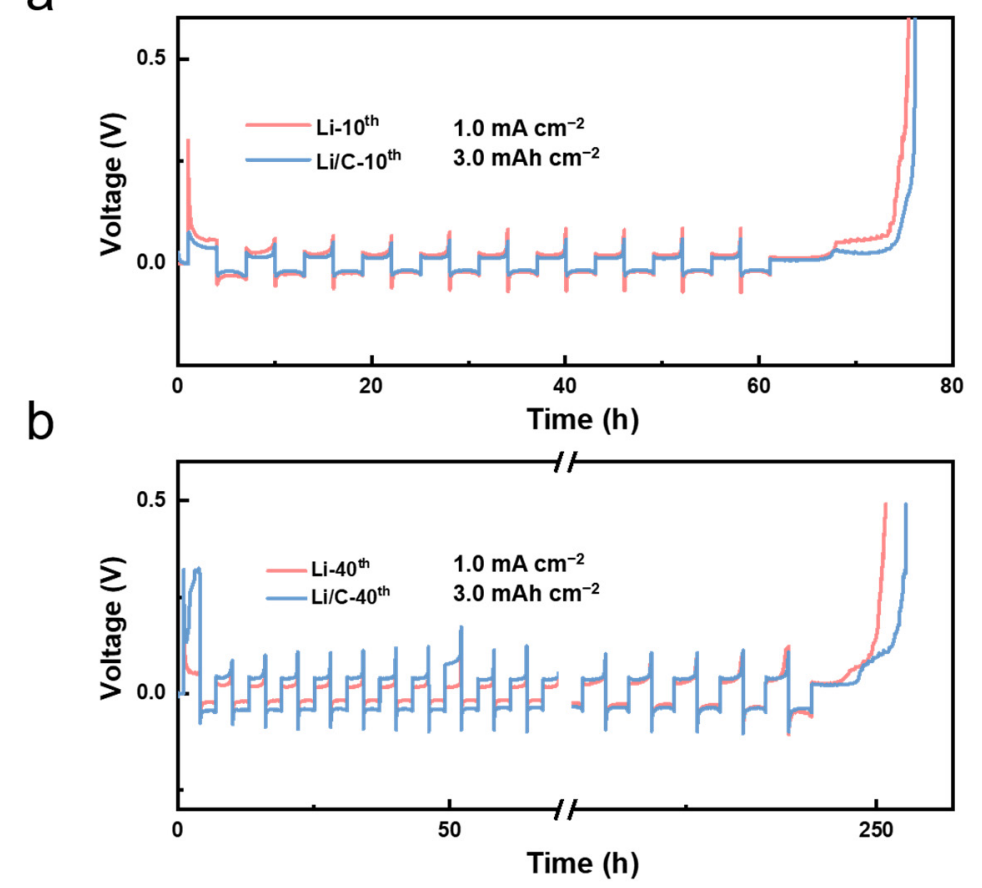

Figure S9. The voltage profiles of the symmetric cells with bare $\mathrm{Li}$ and a $\mathrm{Li} / \mathrm{C}$ composite anode after the $10^{\text {th }}$ and $40^{\text {th }}$ cycle for calculating average CE. 
a

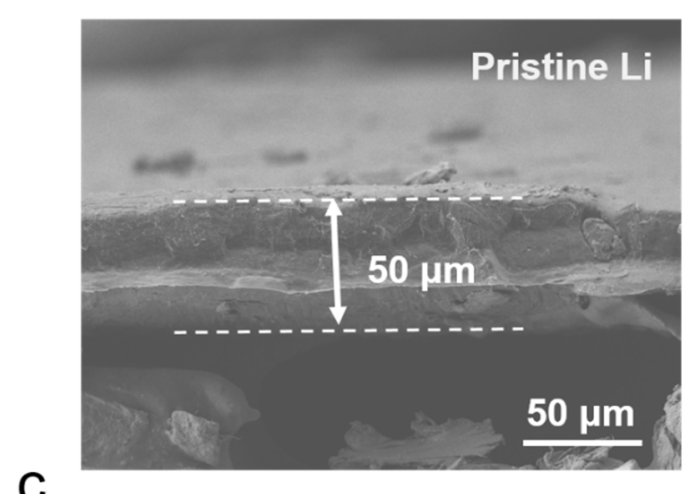

C

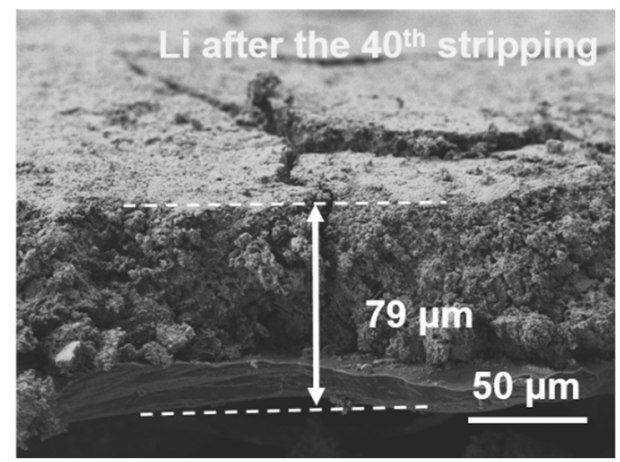

b
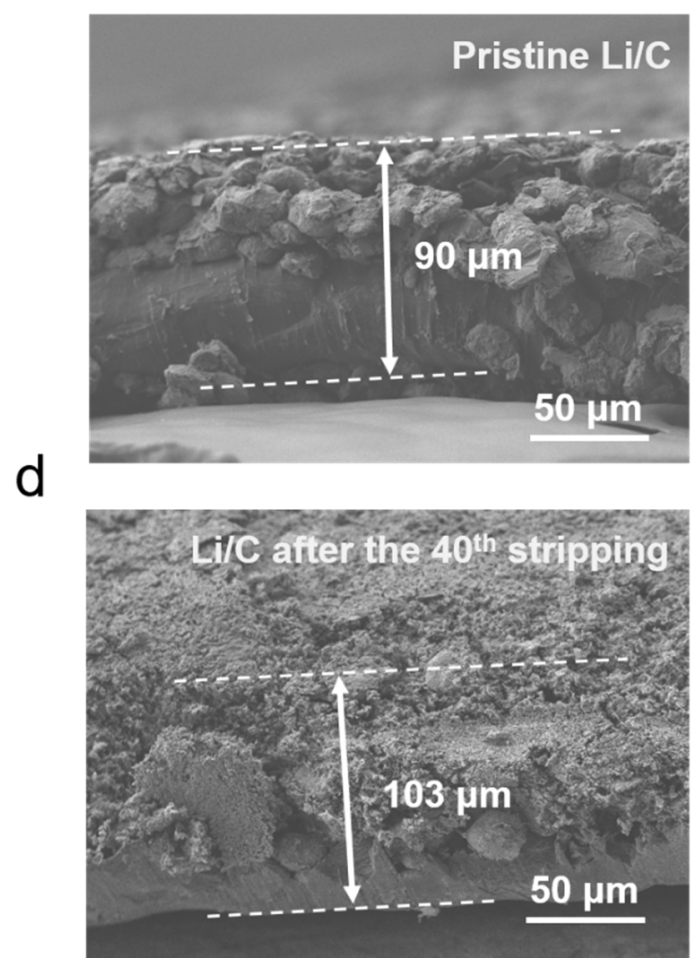

Figure S10. Cross-sectional SEM image of the pristine (a) bare $\mathrm{Li}$ and (b) $\mathrm{Li} / \mathrm{C}$ composite anode, and the (c) bare $\mathrm{Li}$ and (d) $\mathrm{Li} / \mathrm{C}$ composite anode after the $40^{\text {th }}$ stripping. 
a

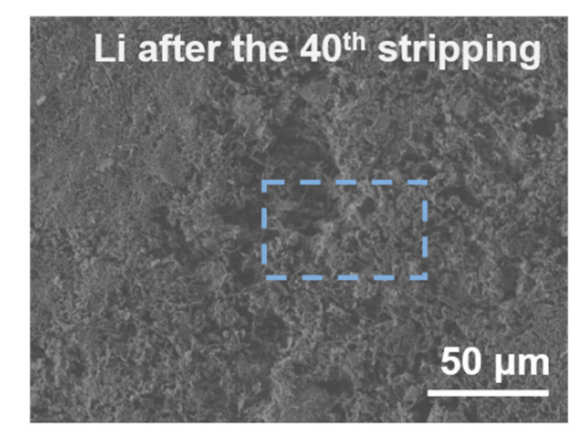

C

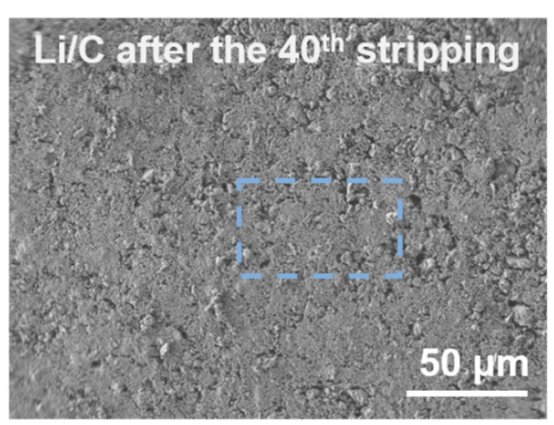

b
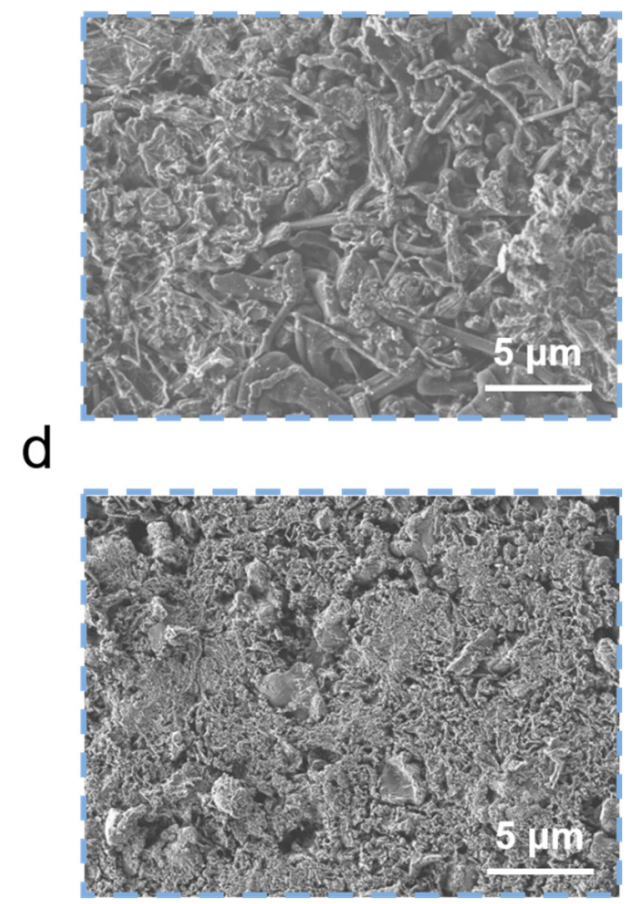

Figure S11. The morphology of (a) bare Li and (c) Li/C composite anode after 40 cycles.

(b) and (d) is the partially enlarged image of (a) and (c), respectively. 


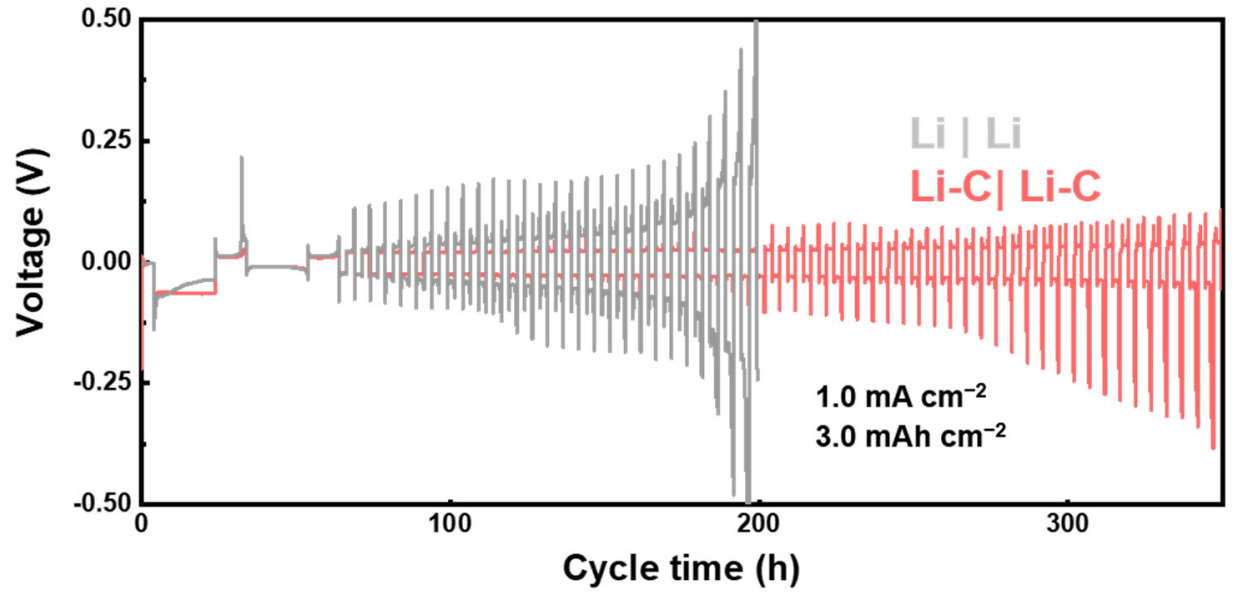

Figure S12. The voltage profile of symmetric cells at a current density of $1.0 \mathrm{~mA} \mathrm{~cm}^{-2}$ and a capacity of $3.0 \mathrm{mAh} \mathrm{cm}^{-2}$. 


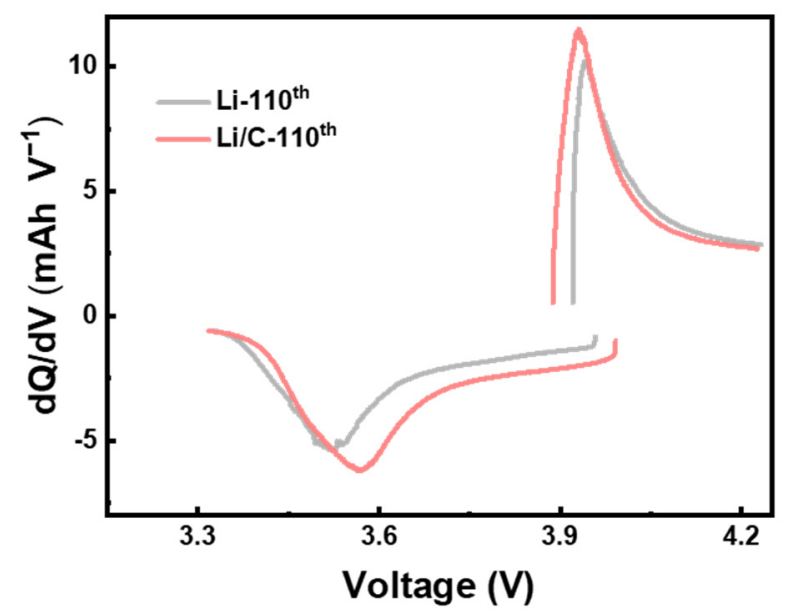

Figure S13. The profile of $\mathrm{d} Q / \mathrm{d} V$ vs. $V$ for the full cell with a bare $\mathrm{Li}$ and $\mathrm{Li} / \mathrm{C}$ composite anode. 


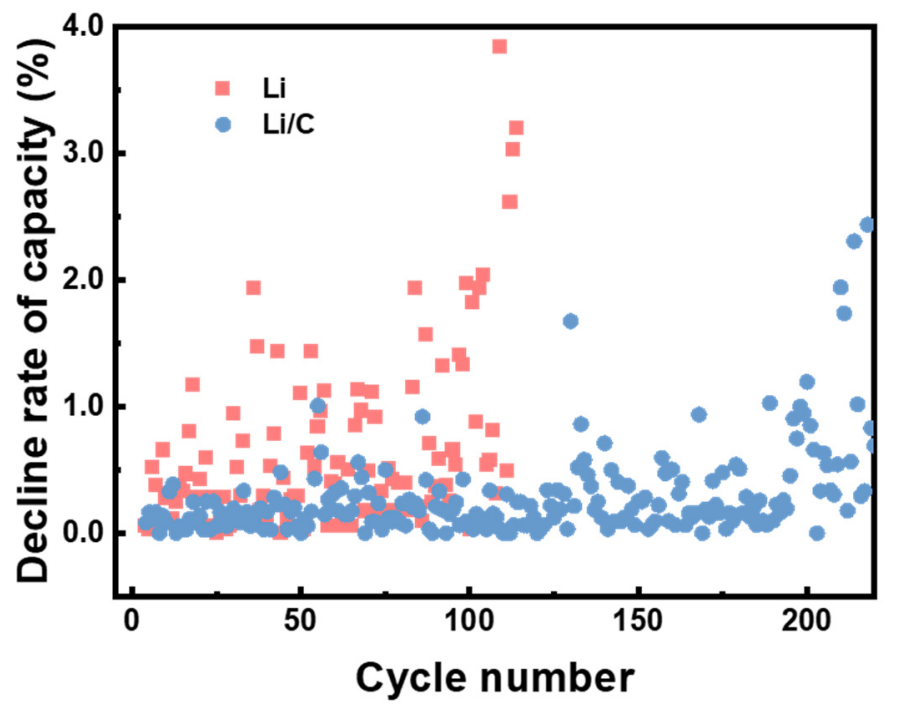

Figure S14. The decline rate of capacity in full cells with a bare $\mathrm{Li}$ anode or $\mathrm{Li} / \mathrm{C}$ composite anode. The decline rate of capacity was calculated by dividing the capacity difference between two adjacent cycles by the capacity of the previous cycle for normalized comparison. 


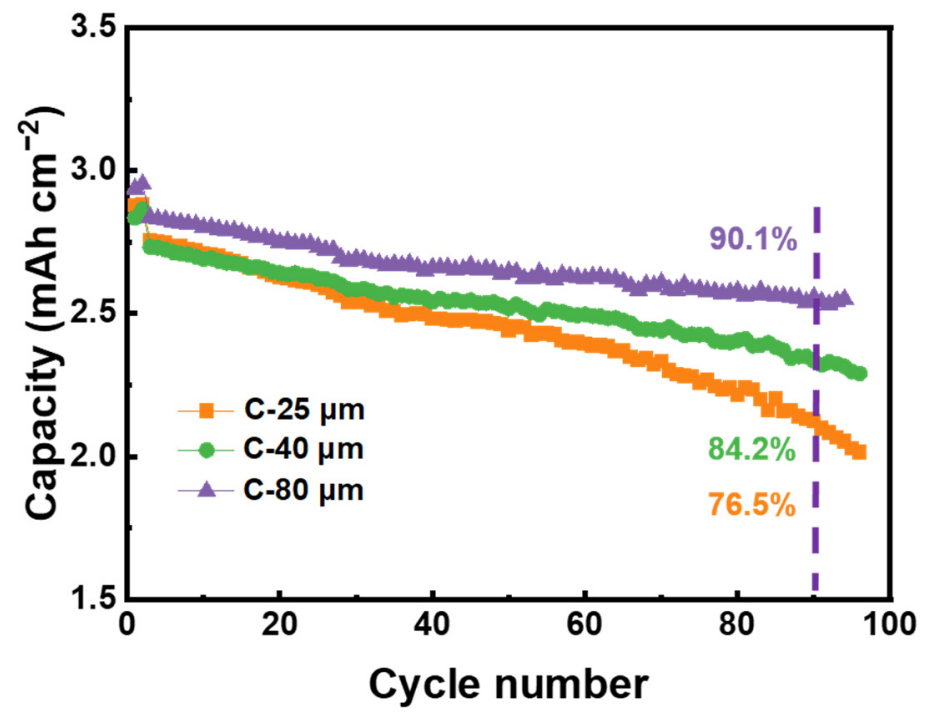

Figure S15. The cycle performance of the batteries based on $\mathrm{Li} / \mathrm{C}$ composite anode with different thicknesses of graphite. The thickness of the graphite in $\mathrm{Li} / \mathrm{C}$ composite anode was 25,40 , and $80 \mu \mathrm{m}$, respectively. The electrolyte was $1.0 \mathrm{M} \mathrm{LiPF} 6$ dissolved in $\mathrm{FEC} / \mathrm{DMC}$ (1:4, by volume). 


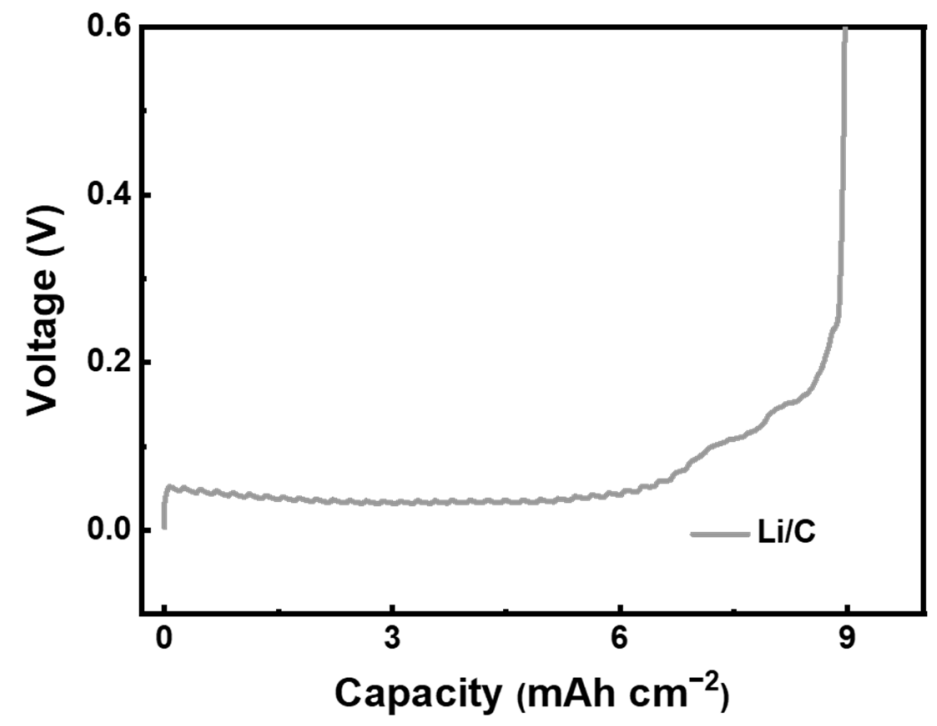

Figure S16. Typical Li stripping curves of $\mathrm{Li} / \mathrm{C}$ composite anodes at a current density of $0.5 \mathrm{~mA} \mathrm{~cm}{ }^{-2}$. The capacity of Li stripping is around $8.7 \mathrm{mAh} \mathrm{cm}^{-2}$ and the mass of the electrode is $7.7 \mathrm{mg} \mathrm{cm}^{-2}$. And the practical specific capacity of graphite is $340 \mathrm{mAh}$ $\mathrm{g}^{-1}$. Therefore, the whole specific capacity of the composite anode with a thickness of $50 \mu \mathrm{m}\left(2.7 \mathrm{mg} \mathrm{cm}^{-2}\right)$ is around $1500 \mathrm{mAh} \mathrm{g}^{-1}$.

$$
Q_{c}=340 \mathrm{mAh} \mathrm{g}^{-1}+\frac{8.7 \mathrm{mAh} \mathrm{cm}^{-2}}{7.7 \mathrm{mg} \mathrm{cm}^{-2}} \approx 1500 \mathrm{mAh} \mathrm{g}^{-1}
$$

